\title{
De la teoría de las formas de gobierno a la evolución del poder: léxico científico y complejidad en la ciencia política*
}

\author{
From the Theory of Forms of Government to the \\ Evolution of Power: Scientific Language and \\ Complexity in Political Science
}

José Javier Blanco Rivero ${ }^{* *}$

Recibido: 2 de agosto de 2016

Aprobado: 30 de noviembre de 2016

Publicado en línea: 10 de octubre de 2017

\section{Resumen}

Este artículo tiene el objetivo de formular una crítica epistemológica a la ciencia política, cuestionando la ontología subyacente a su modo de formación conceptual. Estos modos de formación conceptual, fundados en una larga tradición intelectual, dan pie a un conjunto de obstáculos epistemológicos que cobran mayor evidencia en las tipologías de los regímenes políticos. Con el objeto de formular un correctivo, se sugiere una teoría de la evolución del poder basada en la sociología política de Niklas Luhmann. En el análisis epistemológico e histórico de la ciencia política, se emplea una metodología de la arqueología del saber foucaultiana y la escuela de Cambridge de historia intelectual, así como algunos elementos de la lógica formal subyacente a la teoría de los sistemas, mientras

\section{Abstract}

This text has as the objective of formulating an epistemological critique of political science, questioning the ontology underlying its conceptual framework. These conceptual settings bear some epistemological obstacles that are mostly evident in political regimes' typologies. With the aim to formulate a correction, I resort to the theory of power evolution based on Niklas Luhmann's political sociology. In the epistemological and historical analysis of political science I employ a methodology of the Foucaultian archeology of knowledge and the Cambridge School of intellectual history, as well as some elements of formal logics underlying systems theory; while in its purposive part the article bears upon a socio-systemic vision of socio-cultural evolution. It is concluded that this

doi:10.11144/Javeriana.papo22-2.tfge

* Artículo de revisión.

** Licenciado en Estudios Políticos y Administrativos por la Universidad Central de Venezuela y doctor en Ciencias, Mención Ciencias Políticas, por la misma universidad. Profesor agregado del Departamento de Ciencias Sociales de la Universidad Simón Bolívar. Correo electrónico: joseblanco@usb.ve 
que la parte propositiva se apoya en una visión sociosistémica de la evolución sociocultural. Se alcanza la conclusión general de que el lastre ontológico del lenguaje científico de la política podría remediarse con un cambio de paradigma hacia la complejidad, el cual desarrolle un nuevo lenguaje que se apuntale bajo presupuestos no ontológicos. Esto se lograría replanteando problemas cruciales como la relación entre el poder como medio de comunicación y la diferenciación funcional de un sistema político. Se perfila como uno de los aportes más destacados del artículo la categoría de configuraciones cíclicas del poder, la cual pretende describir con mayor fidelidad el conjunto de problemas que usualmente ha sido objeto de la teoría de los regímenes políticos.

\section{Palabras clave}

ciencia política; poder; medio de consecución; evolución; ontologismo; complejidad

\section{Cómo citar este artículo:}

Blanco, J. J. (2017). De la teoría de las formas de gobierno a la evolución del poder: léxico científico y complejidad en la ciencia política. Papel Político, 22(2), 395-425. https://doi. org/10.11144/Javeriana.papo22-2.tfge ontological burden can be left behind by shifting to a complexity paradigm which develops a new and non-ontological language. This could be achieved by reframing crucial problems, with relation to power as a means to communicate and the functional differentiation of a political system. A salient contribution of the text is the category of cyclical configurations of power, which intends to describe with higher fidelity the set of problems that has been usually object of political regimes theory.

\section{Keywords}

political science; power; evolution; success means; ontologism; complexity 


\section{Introducción}

En este artículo, se argumentará que, para ganar nuevas perspectivas e interpretaciones sobre la dinámica de la política doméstica contemporánea, es necesario transitar de un paradigma que se concentra en definir, caracterizar y clasificar regímenes políticos, sistemas de gobierno, sistemas políticos o sistemas de partidos, hacia un nuevo paradigma que considera el poder como un medio de consecución, capaz de autoorganizarse, simbolizarse e instrumentalizarse y adquirir tal complejidad estructural que lo impulsa a evolucionar en el tiempo histórico.

Ello implica dejar de comprender el poder como una propiedad adscrita a organizaciones, grupos (p. ej. los terratenientes) o personas (p. ej. el caudillo) y entenderlo como una configuración de circuitos marcados por flujos y contraflujos. Aprehender el poder en su evolucionar implica también aceptar que las descripciones que pudiesen darse por válidas en el contexto de formas primarias de diferenciación por estratos (sociedades estamentales, de castas o de clases) han perdido precisión en una sociedad moderna diferenciada por funciones. De manera que fenómenos como la cosificación del poder en la tierra (Hintze, 1968, p. 41; García-Pelayo, 1991a, p. 1050), que apuntalaron formas de organización del poder dependientes de la jerarquía social, han venido a dar paso a formas más complejas de organización del poder en las cuales este se ordena autorreferencialmente (Luhmann, 1997, pp. 61-66).

Pero antes de desarrollar una teoría del poder es menester preparar el camino. En primer lugar, se habrá de considerar la ciencia política contemporánea como el resultado histórico de un conjunto de discursos que han dejado su huella en el lenguaje científico-político moderno, entre otras cosas, en la forma y manera en que se construyen conceptos y en las relaciones lógicas que los articulan. En segundo lugar, se hará énfasis en un problema epistemológico fundamental que rige esa forma de pensar y la constriñe: la ontología política que impide concebir adecuadamente los problemas del cambio y la transformación de los órdenes, los regímenes políticos, los sistemas o las formas de gobierno. Solo entonces se podrán echar los cimientos de una teoría del poder que permita responder al problema del cambio político y a la forma de concebir la organización y función de lo político, recurriendo a la noción de la evolución del poder. Partiendo de allí, se podrá describir la política como un sistema funcional-mundo. Posteriormente, se sustituirá el polémico concepto de Estado por el de formas de organización del poder, con el propósito de profundizar en el problema de la circularidad del poder, introduciendo la categoría de configuraciones cíclicas del poder y distinguiéndolas en función de su estabilidad dinámica entre estables, hiperestables e inestables. 


\section{Los lenguajes científicos de la política y sus modos de formación conceptual}

La ciencia política moderna se ha formado en torno a una pretensión de cientificidad que la distingue de los lenguajes con pretensión de conocimiento sobre lo político que han evolucionado en el pasado. Esta pretensión de cientificidad apuntalada en el estudio de los datos y del comportamiento empíricamente observable y cuantificable determina también lo que se considera una teoría científica y cómo esta ha de ser formulada. De modo que, al sostener que existe cierta continuidad entre la tradición de la teoría de las formas de gobierno y la moderna ciencia política, tal afirmación no se fundamenta en la persistencia de un mismo conjunto de pretensiones de cientificidad, ni de un mismo modo de entender y formular las teorías sobre los fenómenos políticos, sino que el apuntamiento se dirige a algo mucho más sutil: la formación de un objeto de estudio definido como política, el desarrollo de un léxico para su referencia y un modo típico de definir y delimitar sus problemas obedece - dicho en términos foucaultianos- a la evolución histórica de una formación discursiva que se autorregula en la formación enunciativa y en los demás aspectos recién señalados (Foucault, 2006a, pp. 33-130; Cansino, 1998, pp. 165-173). Dicho de otra manera, aquello que se entiende regularmente como pensamiento político no es cosa distinta del lenguaje que lo constituye, y sus estructuras persisten como patrones de larga duración que continúan ejerciendo su efecto, aun cuando la superficie de las diversas y variopintas construcciones referenciales de objetos de estudio, definiciones conceptuales y teorías científicas muestren una dinámica cambiante.

La ventaja de partir de la teoría de las formas de gobierno para realizar este análisis discursivo consiste en su reconocida longevidad en la historia político-intelectual de Occidente. Incluso hoy en día, aun cuando el rango de temas, problemas y enfoques sobre lo político ha cambiado y crecido, no puede perderse de vista su influencia sobre la ciencia política contemporánea. Y es que no se trata de una teoría propiamente dicha, sino de una tradición de discurso.

Pero antes de avocarnos a la tarea planteada, es menester explicitar el instrumental analítico que nos servirá de ayuda. Aquí nos separamos un poco de la jerga foucaultiana.

Bajo el entendido de que el lenguaje es un medio de comunicación constituido, a su vez, en el medio universal del sentido, partimos del supuesto de que el lenguaje como medio está estructurado por diversos niveles de generalización del sentido y así se diferencia el sentido propiamente dicho del sentido lingüístico (significado). Hablamos, entonces, de cinco formas de generalización lingüística del sentido y, por tanto, de cinco formas de condensación y desplazamiento de significados: los campos semánticos, las estructuras semánticas, los discursos, los conceptos y los lugares comunes. Estas formas de generalización lingüística del sentido tienen la facultad de incrementar simultáneamente la variedad y la redundancia y dotan a los sistemas sociales de mayor capacidad de 
procesamiento de información y, por ende, de mayor complejidad estructurada (Blanco, 2012, 2013). De modo que la evolución sociocultural depende en no poca medida de las prestaciones del lenguaje (Luhmann, 1997, 2008).

Los campos semánticos constituyen el ámbito de referencia más amplio, pues, al referirnos a ellos, nos remitimos al conjunto de la red de significaciones que delinea los contornos de un universo cultural. Estos campos semánticos son identificables y discernibles entre sí por la operatividad de una estructura semántica guía (o como lo llamaría Luhmann, una diferencia directriz), a partir de la cual se encadenan otras estructuras semánticas que crean campos gravitacionales de significación o nodos en la red (conceptos), los cuales son formados y actualizados por la constante y repetida enunciación (lugares comunes) y por los patrones reconocibles que de allí surgen (discursos) (Blanco, 2012, 2013).

Ahora bien, buena parte de los discursos de la política, o lenguajes políticos si seguimos la terminología de Pocock (1989, 1990, 1995), han evolucionado a partir de lo que denominamos campo semántico naturalista. Como su nombre lo indica, este campo semántico está caracterizado por la estructura semántica del concepto de naturaleza, a saber, la diferencia entre generación y degeneración. Esta estructura semántica guía ha creado nexos sólidos con otras estructuras semánticas como ser/no ser, materia/ espíritu, cuerpo/alma, razón/pasión, virtud/vicio y mutabilidad/inmutabilidad, por nombrar las principales (Blanco, 2013). Del cruce de estas estructuras semánticas, han emergido lugares comunes que fácilmente podemos reconocer dando forma a una tradición de discurso que conforma el espinazo del "pensamiento político occidental”. Podemos señalar algunos de estos lugares comunes:

- La naturaleza del hombre es inmutable/la naturaleza del hombre es perfectible.

- El hombre es egoísta por naturaleza/el hombre es sociable por naturaleza.

- Las sociedades políticas se inscriben dentro del orden natural/las sociedades políticas son creaciones artificiales del hombre.

- Los cuerpos políticos están sujetos a la degeneración/se puede revertir la degeneración de los cuerpos políticos con su correcta constitución (constitución mixta).

- La mejor forma de gobierno es aquella ceñida a las costumbres del pueblo/la mejor forma de gobierno es la constitución mixta (república)/la mejor forma de gobierno es la monarquía/la mejor forma de gobierno es el gobierno representativo.

- El gobierno es capaz de reformar las costumbres del pueblo con la legislación/la estabilidad del cuerpo político depende de que las leyes respeten las costumbres del pueblo.

Entre estos y algunos otros lugares comunes que hemos dejado por fuera, se han configurado distintos lenguajes o discursos sobre la política. Así, tenemos el lenguaje de la ciencia civil (Skinner, 1996), el lenguaje republicano (Pocock, 2002; Skinner, 1998a; 
Castro Leiva, 2009; Van Gelderen y Skinner, 2002), el lenguaje de la razón del Estado (Viroli, 2009; Foucault, 2006b; Skinner, 1998b) o del arte del gobierno (Senellart, 1995), el lenguaje del derecho natural (racional y escolástico) (Tuck, 1979; Chiaramonte, 2004; Rus, 2001; Leal, 2011), el lenguaje de la ciencia política, ciencia social o ciencia de la legislación (Shklar, 1990; Derathé, 1979; Blanco, 2009) y el lenguaje constitucionalista (Tully, 1995), por nombrar aquellos que han sido tipificados por los historiadores intelectuales.

Todos estos discursos han trabajado sobre el concepto de forma de gobierno y así han constituido lo político desde el enfoque particular que este concepto impone. De esta manera la forma de gobierno aparece como un problema duradero. El planteamiento que da auge a la teoría de las formas de gobierno fue el interrogante de cómo estaba distribuido el poder dentro de una polis (Aristóteles, 7,1279b). Desde entonces (y con la importancia que tuvo la tradición grecorromana en la configuración de la semántica sociopolítica en Europa), los temas de las formas de gobierno, cuál era la mejor y cómo lograr la estabilidad de los cuerpos políticos se convirtieron en preocupaciones duraderas que todo filósofo o publicista obligatoriamente abordaba en sus tratados (Bobbio, 2008).

De esta forma, se constituye un modo enunciativo, se crea un sujeto colectivo (el cuerpo político) del cual se predica que es guiado, orientado, dirigido a buen fin (esto es, gobernado) y se establece que existe más de una manera de gobernarlo: según esté distribuido el poder en la sociedad, según lo esté la propiedad como fiel indicador (Harrington, 1987), o según este cuerpo político, entendido como corporación pública integrada por el pueblo, decida si otorga o concede sus derechos de soberanía, y a quién, y si lo hace temporal o indefinidamente (Gierke, 1958). La naturaleza de este cuerpo político se indica que está inscrita en el orden natural, dado en el cosmos o creado por Dios, o que como cuerpo artificial es la creación del hombre para fundar la sociedad y la vida en común (Skinner, 1993). Como todo cuerpo natural, está sujeto a las leyes de generación y degeneración; pero, si se trata de un cuerpo artificial, ¿̇podría este evitar la degeneración? Esto se hace depender de la pregunta si el cuerpo político está bien constituido o no, y esta pregunta, a su vez, se ramifica en el tema de si un cuerpo debe constituirse de una vez desde su fundación (inmutabilidad) o si a medida que cambien sus costumbres debiesen cambiar también sus leyes y su gobierno (mutabilidad).

Como la forma de constituirse un cuerpo político derivó en un problema central, la constitución se convirtió en un concepto fundamental, el cual experimentó un desplazamiento semántico importante en la medida en que a la ley fundamental escrita se le dotó de un carácter fundacional: creaba el cuerpo político como unidad artificial (Stourzh, 1988). Y las costumbres eran la clave, pues estas llevaban directamente a la naturaleza del hombre (que se presupone inmutable), cuyo conocimiento permitiría "leer en el libro de la naturaleza" o desentrañar "los resortes" que controlaban el funcionamiento de la sociedad. 
A partir de aquí la forma de gobierno pierde importancia frente a la constitución, pues esta será concebida como la herramienta para reformar a un tiempo al gobierno y al hombre y sus costumbres. Pero aun con este desplazamiento hacia el lenguaje constitucionalista y sus presupuestos, existe un núcleo que persiste: la referencia a la naturaleza humana, su inmutabilidad y la posibilidad de desentrañar racionalmente los principios o las fuerzas que la dominan.

El lenguaje constitucionalista logró una innovación que fue un paso antes de la formación de un nuevo tipo de cientificidad. Partiendo de la idea de que existen principios políticos deducibles racionalmente, independiente de la forma de gobierno (Constant, 2010), se presumió que, incluso, si las costumbres del pueblo degeneraban, cuando un Estado se había dotado de una buena constitución que dividía sus poderes y garantizaba la libertad individual, la longevidad y estabilidad del cuerpo político quedaban aseguradas. Desde entonces, toda perturbación de la estabilidad de la vida pública sería atribuida a la ausencia de libertad (facultad consustancial al hombre, un derecho natural). Lo fundamental aquí es que la naturaleza humana ha sido supuesta como constante, y la ciencia política se ha concentrado en las instituciones responsables del orden social y político y cuáles son los principios o leyes que las rigen. En esta misma línea de pensamiento, el poder solía ser concebido como un medio para alcanzar un fin (el bien común, el orden, etc.) o como la expresión de la voluntad de un hombre o de un colectivo (tanto como corporación pública como en el nuevo sentido que llega a adquirir el concepto de pueblo como soberano).

Si bien la ciencia política moderna ha pretendido dejar de lado los razonamientos históricos y jurídicos y fundarse en el estudio del comportamiento político, observable, regular y mensurable, más allá de estas pretensiones epistemológicas y teóricas persiste un modo de predicar lo político que tiene nolens volens a la naturaleza humana como centro, aunque ya no como un problema moral, sí como un problema de la construcción inferencial de conocimiento a partir de la observación de la conducta humana. Y esto atañe también al poder, el cual adquiere una nueva dimensión al ser contemplado desde un punto de vista conductista. El problema del poder se densifica al incluir la dimensión de los intercambios de gratificaciones simbólicas y materiales entre actores (quién obtiene qué a cambio de qué).

Este breve repaso histórico pretende demostrar que el modo de enunciación y las reglas que regulan las expresiones inteligibles de conocimiento científico-político en la actualidad forman parte de una evolución histórica que se hace presente hoy día con 1) la vigencia del supuesto de la centralidad de la naturaleza humana para el problema del poder y de lo político y 2) por intermedio de las estructuras semánticas ser/no ser y mutabilidad/inmutabilidad que informan las reglas de formación conceptual. Estos presupuestos ontológicos establecen como ley que para definir algo hay que identificar su esencia, lo cual consiste en clasificarla en un género y señalar su diferencia específica; 
y esta esencia debe permanecer inmutable a lo largo del tiempo para que se pueda estar hablando de la misma cosa, puesto que, si la esencia cambia, ocurre una transformación de un ser a otro. En este sentido, se puede hablar, en términos generales, de una ontología política. A continuación, se explicará de qué modo esta se manifiesta concretamente en la elaboración teórica y cuáles son los límites que impone al conocimiento.

\section{La ontología política como obstáculo epistemológico}

\section{El concepto de obstáculo epistemológico}

El concepto de obstáculo epistemológico desarrollado por Bachelard (2007) parte de un estudio psicológico o psicoanalítico de las condiciones bajo las cuales el espíritu adquiere conocimientos. La tesis del autor consiste en señalar que el punto de partida nunca es cero; la adquisición de conocimientos siempre se produce frente a conocimientos ya poseídos, por más rudimentarios que sean. Por tanto, el conocimiento nuevo se adquiere en contraposición al conocimiento previo. Pero esta vía a la adquisición de conocimientos está plagada de dificultades, pues el conocimiento tiende a la inercia y la cerradura; el espíritu mismo, una vez inquieto y curioso, sucumbe en su madurez al instinto de conservación. Esto ocurre porque las ideas que una vez resultaron estimulantes tienden a darse por más claras en cuanto incrementan su utilidad, y así llegan a valorizarse indebidamente. Incluso el mismo afán de oponer un conocimiento frente al otro puede llevar a la bipolaridad de los errores, es decir que la necesidad de legitimar el nuevo conocimiento con la polémica conlleve la conversión de las objeciones en objetos y de las críticas en leyes.

Para Bachelard, existen diversos tipos de obstáculos epistemológicos: la experiencia básica, el conocimiento general, el obstáculo verbal, el conocimiento unitario, el obstáculo sustancialista y el obstáculo animista. Entre estos, nos interesan, en particular, el obstáculo verbal y el obstáculo sustancialista, los cuales se encuentran estrechamente imbricados. Por obstáculo verbal, Bachelard (2007, p. 24) se refiere a "la falsa explicación lograda mediante una palabra explicativa, con esa extraña inversión que pretende desarrollar el pensamiento analizando un concepto" en vez de "implicar un concepto particular en una síntesis racional”. Esto significa, desde la perspectiva del autor, que el mero análisis semántico no explica la realidad. Junto a este, el sustancialismo se apoya en una "filosofía fácil" que se caracteriza por "la monótona explicación de las propiedades por la sustancia" que frena "la investigación en lugar de provocarla". A lo que más adelante añade: "Pareciera que es suficiente una palabra griega para que la virtud dormitiva del opio que hace dormir deje de ser un pleonasmo. El acercamiento de dos etimologías de genios diferentes" efectúa "un movimiento psíquico que pasa por ser la adquisición de conocimiento”. Y espeta: “Toda designación de un fenómeno conocido con un nombre científico aporta una satisfacción a un pensamiento perezoso" (pp. 115-116). 
A pesar de la diversidad de formas de manifestación, el obstáculo sustancialista puede identificarse bajo tres caras: el sustancialismo de lo oculto, el sustancialismo de lo íntimo y el sustancialismo de la cualidad evidente. Pero, en sus distintas expresiones, lo definitivo es que la pretensión de identificar sustancias en las cosas y en los fenómenos, como nos dice Bachelard (2007, p. 123), "torna inadecuada la variación de la experiencia. Si encuentra diferencias en las manifestaciones de la cualidad íntima, las explica de inmediato por una intensidad variable”. El sustancialismo estrecha las preguntas científicas (y, por ende, el avance de la ciencia), porque, al obligarnos a creernos en posesión de la "raíz sustancial del fenómeno observado [...] no se siente la necesidad de hacer variar las circunstancias que se estiman más o menos accidentales, más o menos superficiales" (p. 126). Asimismo, esta pretensión lleva a la necesidad de "sustantificar" las cualidades, de manera que las "cualidades puramente metafóricas" aparecen "planteadas como esenciales" o se conduce a la tendencia de "que todo principio activo cree una sustancia" (p. 130).

Podría parecer una excentricidad traer a colación los argumentos de Bachelard en el contexto actual, no obstante, sus ideas se compaginan con las de autores contemporáneos como Latour (2013). Pretendiendo realizar una antropología de los modernos, Latour se embarca en una investigación para descubrir los distintos modos de existencia. El problema es peculiarmente intrincado, pues el origen de nuestras dificultades está en nuestro mismo lenguaje, el cual presupone una relación entre él mismo y la existencia. Esto lleva al autor a distinguir entre los problemas de la extensión de las cadenas de referencia, que nosotros como actores creamos al emplear el lenguaje, y los problemas de reproducción referidos a las condiciones de persistencia de las cosas. Al tratar de desmalezar el trecho que une lenguaje y existencia, Latour (2013) está atacando también las epistemologías ontológicas que dominan nuestro lenguaje científico.

Desde la lingüística, la corriente integracionista liderada por Roy Harris también ha formulado críticas muy parecidas. Para Harris (1981), el sustitucionismo (surrogationism) o telementalización (telementation) es una mitología del lenguaje que ha impedido o detenido el desarrollo de las teorías del lenguaje. La telementalización consiste en el prejuicio de que existe una correspondencia uno a uno entre palabras y objetos/ideas, por lo cual proferir una palabra determinada evoca de manera unívoca un objeto o una idea.

Podríamos añadir, incluso, que el moderno paradigma de los sistemas complejos apunta a superar los obstáculos epistemológicos sustancialistas en cuanto parte del principio de estudiar las relaciones entre los elementos y las propiedades emergentes del conjunto, en vez de identificar las propiedades y características de los elementos individuales que integran un sistema.

Veamos, entonces, cómo se ha manifestado este obstáculo sustancialista en la ciencia política contemporánea y cuáles son los problemas que enfrenta restringiendo la 
formulación de nuevos interrogantes que estimulen la reproducción autopoiética del sistema de la ciencia, en el sentido de Luhmann (1992).

\section{La ciencia política contemporánea y su ontologismo}

Hablar de la ciencia política como unidad es problemático. La ciencia política contemporánea de ningún modo ha estado dominada por las pretensiones empiristas y behavioristas que guiaron su inscripción en la cientificidad. Nunca pudo la ciencia política deshacerse de la filosofía, la historia intelectual, los estudios constitucionales y jurídico-institucionales, entre otros. Y las diferencias en programas de estudio y preferencias teórico-metodológicas entre los distintos países han sido siempre parte del panorama (Johnson, 1991; Easton, Graziano y Gunnell, 1991). Las críticas hacia el método empírico-cuantitativo han estado siempre a la orden del día, o bien para tratar de conferirle un justo lugar (Easton, 1968), o bien para reafirmar la ciencia política como ciencia normativa (Voegelin, 2006). Por tanto, el argumento no ha de presentarse sobre el nivel teórico, sino sobre los modos enunciativos del lenguaje científico de la política (Foucault, 2006a), aunque naturalmente para ello no se pueda prescindir de las teorías como material empírico.

No es posible comenzar sin decir algunas palabras sobre la importancia que en el campo tuvo la teoría de los sistemas. Principalmente, porque tuvo la potencialidad de constituirse en un léxico científico desontologizado, pero pereció aplastada por el peso de la tradición ontológica.

Las estructuras semánticas y los nexos de sentido que dan lugar al concepto de sistema marcan una distancia frente al ontologismo. Las estructuras semánticas todo/partes, variable dependiente/variable independiente y elemento/relación daban pie -como referencia excedentaria de sentido- a la hipótesis de un todo caracterizado, no por la suma de las propiedades de sus elementos, sino por el comportamiento emergente que producían esas partes en conjunto. Pero un concepto por sí solo no hace un léxico, por lo cual las distintas enunciaciones del concepto y sus intentos de definición cayeron en el campo gravitacional del ontologismo político.

Desde esta perspectiva, la introducción del concepto de sistema político significó una simple traducción al lenguaje de la cibernética de las antiguas preocupaciones por la estabilidad constitucional o institucional. La propia autoidentificación de la cibernética como ciencia del control establecía nexos asociativos con el tradicional concepto de gobierno (Deutsch, 1980), y de esta forma ella misma contribuyó a su esterilidad al renunciar a una teorización más radical, es decir, renunciar a pensar cibernéticamente la política partiendo de cero.

Una diferencia fundamental frente a la tradición es que el sistema político, dominado por la referencia al todo, era concebido como algo más que el gobierno; ahora integraba a los grupos de interés, los lobbies y los partidos políticos, donde la importancia de estos 
últimos será considerada tan grande que las relaciones entre ellos caracterizarían los tipos de sistemas políticos (Easton, 1968).

Posteriormente, la desconfianza hacia el funcionalismo hizo que el análisis de los sistemas políticos deviniese el análisis conjunto del sistema de partidos políticos, el marco constitucional, los grupos de presión, los grupos de interés, los movimientos sociales y el sistema electoral dentro de un Estado nación. Consecuentemente, el concepto de sistema perdió alcance teórico y quedó como una categoría marco, que servía para delimitar un campo de fenómenos interrelacionados.

La teoría general de los sistemas fracasó en su pretensión de dotar la ciencia política de un marco teórico unitario y, sobre todo, de formular una teoría general de la política. Por tanto, la posibilidad de desarrollo de un léxico científico-político con presupuestos alternativos a los ontológicos ha quedado por el momento fuera de juego.

Tras el naufragio de la teoría de sistemas, el panorama de la ciencia política consistía en un archipiélago de teorías de mediano rango, cuando no un prolongado ejercicio de correlación estadística entre variables. En este escenario, la mejor forma de evidenciar el sustancialismo en la ciencia política contemporánea consiste en tomar ejemplos puntuales de diversos autores.

En primer lugar, podemos encontrar presupuestos ontologistas a la hora de definir el objeto de estudio. Así, tenemos el trabajo de Guevara (1997), quien, para apuntalar su tesis consistente en la contradicción entre la estatalidad y la democracia, se avoca a determinar la esencialidad de cada uno de estos términos. En ese tenor apunta: "Entenderemos por esencial lo siguiente: dado X, si (a, b, c) es el conjunto de variables que lo definen, es esencial aquella variable del conjunto, b por ejemplo, que sin su presencia $\mathrm{X}$ deja de ser $\mathrm{X}$ para constituir otra cosa distinta” (p. 1). Más adelante señala que aquella variable esencial de la democracia es la participación (p. 50). Este mismo proceder lo podemos observar de forma soterrada en Held (1997), quien reduce la democracia al principio de la autonomía.

En segundo lugar, de manera más palmaria, podemos encontrar los presupuestos sustancialistas en el proceder taxonómico, modélico o tipológico, que es frecuente encontrar en todo tipo de textos de ciencia política. En un caso bastante obvio, se exhiben las estructuras semánticas del campo semántico naturalista, tal como fueron configuradas en la tradición de la teoría de las formas de gobierno. Así es como Barber (2004, p. 109) afirma: "Indeed, it is the hybrid character of American democratic liberalism that gives it its great versatility and its ability to resist degeneration" (Ciertamente, es el carácter híbrido del liberalismo democrático americano que le confiere su gran versatilidad y su habilidad para resistir la degeneración). Aquí vemos el lugar común del gobierno mixto y aquel de la degeneración de los cuerpos políticos siendo evitada por este arreglo institucional. Y cuando agrega en el mismo párrafo que la democracia liberal en Norteamérica, el Reino Unido y partes de Europa continental constituyen excepciones 
extraordinarias a la proclividad tiránica de la especie humana, se completa el otro lugar común sobre las afirmaciones de la naturaleza humana.

La persistencia de los conceptos y lugares comunes, propios de la teoría de las formas de gobierno, se evidencia con particular claridad en la teoría política del totalitarismo. Así, Friedrich y Brzezinski (1975) califican el totalitarismo como un nuevo género de autocracia; Arendt (2004) se refiere al totalitarismo como una nueva forma de gobierno que se caracterizaba por la pretensión de dominación total, cuya esencia era el terror y principio de acción la ideología; pero lo que lo hacía tan brutal era especialmente su pretensión de transformar la naturaleza humana.

Una expresión particular del sustancialismo que señalamos se hace patente en el concepto desarrollado por García-Pelayo (1991b, p. 2713) de tipo representativo. Para el autor, se trata del ejemplar considerado como la "expresión más acabada y perfecta de un conjunto de fenómenos dotados de ciertas semejanzas estructurales” o donde "nos parece que se hacen presentes más clara y distintamente propiedades genéricas o esenciales". Y es que aquí parecieran suscribirse los principios metafísicos clásicos que asocian la esencia al estado de madurez y perfección de la cosa, de tal modo que la esencia del hombre está en su madurez y no en su infancia o senectud. Pues la perfección estaba asociada al fin y a la mayor realización de aquello para lo que se estaba hecho.

Muchas son las tipologías que podemos encontrar que clasifican los sistemas de partidos, regímenes o sistemas políticos siguiendo más o menos abiertamente estos supuestos en la formulación de enunciados científicos. Y así como se establecen tipos, también se fijan especies mixtas o híbridas, al igual que en la tradición.

En este tenor, observamos en las últimas décadas un renovado interés en las formas que adquieren los regímenes no democráticos, con el concomitante problema de su denominación y caracterización: qué tanto se alejan de la democracia, qué tanto se confunden con ella. Es este el ámbito de invención de nuevas categorías -o quizá reinvención de las tradicionales- en la ciencia política contemporánea. Así pues, se habla de nuevos autoritarismos (Guriev y Treisman, 2015), semiautoritarismos (Ottaway, 2003), autoritarismos competitivos (Levitsky y Way, 2010), autoritarismos electorales (Shedler, 2006) o regímenes híbridos (Gilbert y Mohseni, 2011).

Como es bien sabido, el panorama de la ciencia política actual está dominado por el concepto de democracia, pero, como no se ha desarrollado un contraconcepto estable, el opuesto de la democracia ha tenido varios lugartenientes. Así, a la democracia se le ha opuesto la dictadura, el totalitarismo, el autoritarismo, el populismo, entre otros. Pero también el mismo concepto de democracia ha dado lugar a adjetivaciones que oponen modelos de democracia entre sí. De modo que tenemos democracias deliberativas, participativas, radicales, liberales, sociales, representativas, entre otras. En consecuencia, las clasificaciones devienen dicotomías y estas de nuevo en tipologías; y 
lo que guía esta oscilación es la inagotable búsqueda de elementos esenciales junto con sus variables consustanciales.

La dificultad que enfrenta la ontología política consiste en las limitaciones intrínsecas que tiene la lógica ontológica para representarse el cambio y la temporalidad. Básicamente, se trata del supuesto de que si algo cambia deja de ser y de la disputa concomitante -cuando se ha presentado una variación- sobre qué es verdaderamente lo esencial y qué lo accesorio e, incluso, qué tanto afecta la ausencia de ciertos factores accesorios a la esencia. Estos supuestos están configurados por la estructura semántica guía de la temporalidad (mutabilidad/inmutabilidad), de manera que el ser, naturaleza o sustancia de una cosa ha de ser inmutable. Así, por ejemplo, desde que Arendt estableció que el terror era la esencia del totalitarismo y este elemento desapareció tras la muerte de Stalin, ¿dejaba la antigua URSS de ser totalitaria? Así lo creyeron muchos, pero algunos intelectuales checos crearon la categoría de postotalitarismo para describir un totalitarismo sin terror (Rupnik, 1991). La categoría de régimen híbrido se crea también, justamente, con la pretensión de comprender la realidad política de los Estados de Europa del Este después de la caída de la antigua URSS (Levitsky y Way, 2010). Y en lo que a tipos ideales o representativos se refiere, ¿̇cuál lo es del fascismo?, porque el alemán fue el más realizado, pero el italiano fue el original. En las respuestas que dan los historiadores, suele encontrarse incluso un nuevo tipo de ontologismo: el sustancialismo de los orígenes que supone que la esencia de algo se halla en sus comienzos.

En fin, al final del día, el investigador podría preguntarse si no es posible en realidad concebir que aquellos estados de cosas clasificados y sustancializados evolucionan. Y esto no solo para las formas de gobierno/sistemas políticos/sistemas de partido, sino también para el poder, pues, si bien la ciencia política moderna ha descrito el problema del poder respecto de las relaciones entre actores (y aquí ha sumado una dimensión adicional a la clásica formulación de la teoría de las formas de gobierno que atendía solo a la organización, y en un sentido amplio), cuando se plantea definir el poder cae inevitablemente en la trampa ontológica. Es decir, la propuesta que aquí se adelanta consiste en comprender el poder teniendo en cuenta las distintas dimensiones del fenómeno (como la organizativa, la simbólica y la instrumental) que interactúan, varían históricamente y dan lugar a distintas configuraciones. En este sentido, justamente, hablaríamos de una evolución del poder.

La tesis de la evolución no es original en sí, pero en el lenguaje común está plagada de malinterpretaciones y quizá justamente por ello enfrenta muchos prejuicios por parte de la comunidad académica en las ciencias sociales. La clave para trascender un evolucionismo mal entendido y sentar sobre bases sólidas el tipo de planteamiento que se propone pasa por responder a la siguiente pregunta: ¿̇cómo concebir la evolución sin fijar de antemano una unidad de referencia? Unidad que suele identificarse con el predominio 
de un grupo social u otro dentro de determinado territorio. En el momento de hallar esa unidad (e identificarla de este modo), ¿no se cae de nuevo en la trampa ontológica?

\section{La evolución del poder: una interpretación de la sociología política de Niklas Luhmann}

Antes de pasar a la interpretación del planteamiento de Luhmann y disertar sobre la evolución del poder, es menester introducir una diferencia, a saber, aquella entre ontogénesis y evolución (Bateson, 2006). Esto contribuirá a despejar el problema que recién nos planteamos. La ontogénesis u ontogenia es la historia que narra el surgimiento, crecimiento y desarrollo de una esencia, por lo cual se necesita reconocer un núcleo que nunca habría cambiado y que permitiría identificar el fenómeno en cuestión. La evolución, en cambio, implica la transformación de un ser en otros; de esta manera, el concepto de evolución permite vincular cosas diferentes en las dimensiones objetiva y temporal de sentido y al mismo tiempo mantener una narrativa unitaria. El concepto de evolución evita tener que segmentar la historia política entre distintas ontogenias y permite descubrir procesos de mayor amplitud al tiempo que se los incluye en una unidad. Esta unidad es necesariamente paradójica y autorreferente, pues la unidad es la misma evolución; la evolución aprehende la mismidad de lo diferente en cuanto ella misma es la epigénesis de la variedad y la diferencia.

La importancia de este concepto consiste en el distanciamiento que produce frente a una larga tradición que tiende a segmentar temporal y estructuralmente a las distintas sociedades, ubicando a cada una en un peldaño de desarrollo según sea más civilizada, más compleja, más racional -entre otros criterios-que las demás. Y esta es una ventaja que en su obra Luhmann (1998) se encarga de esclarecer: evolución no es desarrollo, evolución no es progreso, evolución no significa necesariamente un telos caracterizado por la mayor complejidad social.

¿Qué fundamentos entonces dan forma a una teoría de la evolución sociocultural? Siguiendo a Luhmann, la teoría de la evolución sociocultural ha de encontrarse en estrecha relación con la teoría de los sistemas sociales - pues esta requiere la diferencia sistema/ entorno para el despliegue de sus mecanismos-y con la teoría de los medios de comunicación (Luhmann, 1991, 1998). Los mecanismos evolutivos son tres: variación, selección y reestabilización. Por variación habrán de entenderse los elementos del sistema que se reproducen desviadamente, esto es, de forma sorpresiva e inesperada. Por selección se denotan las estructuras del sistema, a saber, no un rasgo morfológico o alguna clase de cualidad o propiedad esencial, sino las expectativas que permiten el enlace comunicativo y que escogen aquellos nexos de sentido prometedores para su reutilización o que los rechazan explícita o implícitamente; por tanto, las estructuras habrían de entenderse como la acumulación de selecciones hechas por el sistema y sus efectos en su historia 
propia. Y por reestabilización habríamos de referirnos al estado del sistema tras una selección exitosa (positiva o negativa) (Luhmann, 1998). La reestabilización plantea el problema de la compatibilidad de las estructuras seleccionadas con el sistema. El sistema deberá decidir sobre la compatibilidad a partir de sus propias operaciones (a saber, nuevas variaciones y selecciones) y trazar límites que establecen una frontera entre la complejidad reducida de su lado interno y la complejidad inasible de su lado externo. De esta manera, el sistema puede externalizar las incompatibilidades y compartirlas con otros sistemas en el entorno (lo que no significa que se deshaga definitivamente de ellas), mientras que las compatibilidades adquieren la forma de reemplazos estructurales (Luhmann, 1998).

Dado que el concepto de comunicación es central en la sociología de Luhmann, pues los sistemas sociales producen y reproducen comunicaciones y la sociedad como sistema total consiste en la totalidad de las comunicaciones sociales, la teoría sociocultural de la evolución ha de entenderse como una teoría de la evolución de la comunicación. No en vano, la teoría de los medios de comunicación forma el espinazo de su planteamiento: los logros evolutivos tienen que ver con la garantía de éxito de la comunicación social, bien sea en su reproducción fáctica, bien sea en su aceptación; y la teoría de la diferenciación social se basa en las diferencias comunicativas sistema/entorno, es decir que son la comunicación y sus formas de reproducción las que se diferencian de un entorno ecológico y de otras formas de comunicación (Luhmann, 1991).

Como consecuencia, la teoría de la evolución sociocultural concebida por Luhmann no puede prescindir de la teoría de los medios de comunicación, pues justamente ellos (de consecución y difusión) son descritos por Luhmann (1998) como un mecanismo evolutivo de selección del sistema social. Y dentro de los denominados medios de consecución, se habrá de destacar en lo que sigue el poder.

Que el poder sea considerado por Luhmann como un medio de consecución implica que no debe entenderse como una propiedad o facultad atribuida a los individuos; tampoco como algo que se posee, material o simbólico; ni simplemente como una relación de dominación o subordinación; menos aún como una relación causal entre quien tenga una voluntad y la impone frente a otros que obedecen; y ciertamente, no como cualquier forma de constreñimiento social, de cuya pesada carga el individuo oprimido habría de emanciparse. ¿Qué cosa es entonces el poder, o en una formulación menos ontológica, qué función cumple?

En vista de que requeriría un artículo completo exponer al menos las principales aristas de la teoría del poder en Luhmann, aquí solo seremos capaces de explicar algunas cuestiones fundamentales sobre su función, diferenciación y muy poco sobre su estructura, donde nos interesaremos, especialmente, en la capacidad de formación de sistemas y plantearemos algunos problemas derivados de la concepción del sistema político como sistema mundo. 
El poder es un fenómeno comunicativo, un medio de comunicación, que resuelve el problema de la aceptación de la comunicación empleando la amenaza (velada, latente o manifiesta) con la imposición de sanciones negativas o positivas como condicionante para la acción de alter y ego (esta es su función).

Para los medios de consecución en general, Luhmann identifica el problema de su diferenciación como resultado del empleo de la selección como factor de motivación para la participación en la comunicación. ¿Cómo ha de entenderse esto para el poder? Pues sencillamente como el constreñimiento que sobre las posibilidades de acción y vivencia se imponen, primero, limitando el problema exclusivamente a la coordinación de acciones de alter y ego, y segundo, contribuyendo a especificar esa situación social con ayuda de esquemas de atribución. De esta manera, la especificidad de la situación (y posteriormente, de los condicionamientos actualizados para ella) reduce la incertidumbre y hace plausible el hecho de comprometerse o motivarse a tomar parte. Precisamente, la violencia (o mejor, como dijimos arriba, la amenaza con sanciones positivas - gratificación material- o negativas -imposición de la violencia física-) como alternativa presente, que tanto alter como ego desean evitar, es algo característico de las situaciones de poder y que las separa de la mera influencia o autoridad, aunque los límites no son siempre claros, pues, como lo ve Luhmann (2000), el poder es desde siempre una forma de influencia social, solo que con un mayor potencial de generalización simbólica, diferenciación y riqueza estructural y de allí su éxito evolutivo.

El poder como un fenómeno comunicativo no implica relaciones causales lineales, ni meramente dos partes. El poder involucra a ego, alter y a los terceros capaces de observar esas diferencias (Baecker, 2007), y justamente porque esto configura una situación estratégica donde las posiciones de cada cual han de ser recalculadas en cada instante; el output siempre ingresa de nuevo como input y crea un circuito que se retroalimenta. El poder, entonces, está inscrito dentro de una forma de causalidad circular. Por ello, no se puede hablar del poder en términos tan simplistas como una voluntad que se impone y se hace obedecer, debido a que el otro y la posibilidad abierta de observación de las observaciones desgarran constelaciones con mayores o menores probabilidades de lograr la aceptación de la comunicación en un caso concreto. El tercero excluido es la clave para comprender tanto la necesidad de publicidad para conferir ejemplaridad a las sanciones como el fenómeno de la resistencia cuando la selección de una conducta comunicativa sabotea la selección de información. Y esta posición de observación de segundo orden se ha institucionalizado hoy día como opinión pública (Luhmann, 2000). El poder, en consecuencia, es autorreferencial.

La noción de circularidad del poder no solo tiene un apoyo teórico abstracto, sino que también se apoya en un razonamiento histórico-evolutivo, a saber, la transición hacia una sociedad diferenciada funcionalmente. En una sociedad con una forma de 
diferenciación primaria por estratos, las estructuras de poder estaban acopladas a la estructura social, por tal razón las fuentes de autoridad e influencia basadas en el honor, la posesión de la tierra, el prestigio guerrero, entre otras, fácilmente se traducían en poder político. El poder como medio era incapaz de generar fuentes autónomas de confianza, por lo cual debía apuntalarse en aquellas disponibles en el entorno social. La estructura del poder era jerárquica, justo como la estructura social, y la élite social representaba el sistema como unidad.

Pero en una sociedad funcionalmente diferenciada como la moderna, el poder como medio es capaz de cerrarse de manera autorreferencial, sustituir los contactos externos por puntos de contacto interno, generar de por sí confianza (lo que lleva implícito una tendencia a la inflación del medio) y dar pie a la diferenciación de un sistema funcional para la política. Las relaciones jerárquicas en la estructura social no desaparecen, pero pierden dominancia frente a la lógica funcional. La élite ya no es capaz de identificarse con el sistema; el sistema se hace, por tanto, irrepresentable, pudiendo solo ser observado en su contingencia y desde posiciones, a su vez, contingentes. De ahí ese sentimiento de falta de asidero que muchos describen como predominante en la modernidad (Beck, 2002). Y el incremento de complejidad del medio, entre cuyos factores hay que destacar la codificación secundaria, crea las condiciones para el despliegue de ciclos dúplices: un ciclo y un contraciclo. El primero es el ciclo formal del poder que se impone en casos de conflicto, mientras que el segundo es el ciclo informal del poder que domina la cotidianidad del poder político (Luhmann, 1996, 1997).

Este circuito - según Luhmann - atraviesa tres sistemas de interacción que están a su vez insertos en un contexto organizacional. Se trata de la política, la administración y el público (Luhmann, 1997, 2000, 2010). Se observa el ciclo formal cuando se sigue el libreto político según las reglas establecidas constitucionalmente: en la política, se preparan los consensos, la Administración ejecuta las decisiones y el público evalúa los resultados y cuando está descontento protesta ante los organismos públicos y cuando toca votar castiga o premia a los políticos por su desempeño. Pero el ciclo informal es el que opera regularmente y exhibe más claramente el carácter interactivo de este fenómeno comunicativo, pues involucra las influencias que ejercen los grupos de presión e interés y las necesarias negociaciones entre política y administración, en vista de que cada cual opera con programas diferentes (de fines la primera y condicional la segunda), con lo cual surgen entre ellas barreras temporales, de perspectiva social y de prioridades en los objetivos.

El poder es uno de los medios de consecución con mayor riqueza estructural, pues ha logrado reestabilizar un conjunto de selecciones que han resultado exitosas para sí y para su entorno social; y por exitosa no se quiere decir carente de problemas, sino sencillamente que se ha empleado para la continuación de la reproducción de la comunicación. Luhmann ha resumido estos rasgos estructurales en nueve elementos: 
codificación, autoubicación del código en uno de sus valores, reflexividad procesual, programas, observación de primer y segundo orden, inflación/deflación, símbolos simbióticos, simbolización de la inclusión de lo excluido y formación de sistemas (Luhmann, 1998). Estos constituirían a la vista del autor una suerte de baremo del grado de refinación evolutiva alcanzado por los distintos medios de consecución, sin ninguna pretensión normativa que lo tipifique como telos.

Hasta aquí se ha querido demostrar que la teoría de los sistemas sociales de Niklas Luhmann ha desarrollado un planteamiento según el cual el poder como medio de consecución evoluciona en los sistemas sociales hasta generar, incluso, las condiciones para la diferenciación de un sistema funcional para la política. Pero existe un par de ambigüedades en el planteamiento del autor que es menester aclarar, pues, no solo contribuirían a dilucidar ciertas ideas, sino que fundamentalmente ayudarían en la maduración de la propuesta teórica. Ambas están estrechamente relacionadas.

La primera se puede formular de la siguiente manera: partiendo del hecho de que el poder como medio de consecución da pie a la diferenciación del sistema político, cabe preguntarse ¿̇esa diferenciación se alcanza en el sistema mundo o, como parece dar a entender Luhmann en más de una ocasión, en cada Estado territorial del mundo deben darse las condiciones para que se produzca la clausura operativa de un sistema funcional para la política?

La segunda pregunta tiene que ver justamente con el sistema político-mundo. Como algunos autores han señalado (Stichweh, 2002; Holz, 2003), este es un concepto ambiguo y poco desarrollado y, sin embargo, es un concepto importantísimo dentro de su teoría de la sociedad moderna. La cuestión teórica de mayor inquietud a nuestro juicio es ¿cómo está diferenciado internamente el sistema político-mundo? ¿Es satisfactoria la solución de Luhmann (2000) de una diferenciación interna tripartita entre sistema/ entorno, sistema interestatal y centro/periferia? O cंexiste un arreglo teórico que sea satisfactorio en cuanto a la fidelidad histórica e igualmente estimulante para las inquietudes sociológicas y politológicas?

\section{Formas de organización del poder, estructuras disipativas y configuraciones cíclicas del poder}

Los problemas teóricos que enfrenta Luhmann a la hora de concebir el sistema político como sistema mundo derivan estrechamente de su concepción del Estado, que, según Von Beyme (2002), proviene de su ambigua posición epistemológica frente al constructivismo y el realismo. Luhmann piensa el Estado como un concepto tras el cual se esconden varias funciones y estructuras sociales: el Estado es una organización, pero también una forma de autodescripción del sistema político (es decir, una forma del sistema de representarse artificialmente su unidad), e incluso el elemento segmentario 
integrador de un nivel de diferenciación interno del sistema político y, por ende, un destinatario de la comunicación dentro del sistema político (Luhmann, 1999, 2000).

Pero el problema, a diferencia de lo que piensan sus críticos, se encuentra en que tanto Luhmann como los que examinan su obra, parecen abrevar de una narrativa histórica que construye la historia política a partir de las transformaciones sufridas por el Estado desde sus inicios como Estado territorial hasta el estado de bienestar. Sus supuestos se encuentran, además, en una doctrina del Estado (Staatslehre) que cuenta la historia del Estado a partir de desarrollos individuales.

Ciertamente, la historiografía provee abundantes datos y pruebas de cuán diferentes fueron las condiciones de partida entre los distintos países europeos; al mismo tiempo, señala el papel paradigmático que desempeñaron ciertas naciones, como España, el Reino Unido y Francia, que desarrollaron primero que sus vecinos una estatalidad (Anderson, 1987). Pero si tomamos la perspectiva de una historia civilizacional (Arnason, 2003; Arnason, 2010; Smith, 2002), nos damos cuenta, como han señalado algunos historiadores de las relaciones internacionales (Saeidi, 2006), que el Estado ha evolucionado en sistemas sociales regionales, es decir, el Estado no emergió solitariamente, sino que lo hizo en un contexto donde existían otras unidades político-territoriales que competían con él por recursos, territorios e influencia (Tilly, 1992). El proceso evolutivo del Estado en Europa está enmarcado dentro de un sistema social del orbe cristiano. El sistema social musulmán también contó con una pluralidad de unidades político-territoriales y representó durante varios siglos el sistema social más complejo y diferenciado del globo (Hourani, 2010). Y en el Extremo Oriente vemos cómo la diferenciación de diferentes unidades político-territoriales deriva en más de una ocasión en la constitución de imperios (Franke y Trauzettel, 1989).

Un enfoque como el señalado también pone sobre el tapete el sesgo etnocéntrico de la narrativa de la historia estatal. Fiándonos de la historia del concepto y de las instituciones, el Estado stricto sensu solo emergió en Europa, pero ċacaso otros sistemas sociales no desarrollaron equivalentes funcionales?

La solución a este problema yace en la interpretación de la evolución del poder. El problema que da lugar a la evolución del poder como medio de consecución consiste en cómo condicionar la selección de modo de convertirla en factor de motivación, y ello bajo la dimensión de sentido que enlaza tanto las acciones de ego como las acciones de alter (Luhmann, 1998). Este es un problema universal que se presenta en todo sistema social, pues toda sociedad ha de plantearse cómo resolver el problema de la coordinación de acciones. Este se conjuga con distintas constelaciones de atribución (Luhmann, 1998) que varían de un contexto cultural a otro. De la tradición grecorromana, por ejemplo, hemos heredado el concepto latino de dominio, el cual describe relaciones de sujeción personal basadas en la posesión de la tierra. La evolución de estas constelaciones de atribución es de gran importancia, porque de allí emergerán los códigos capaces de incrementar 
el grado de complejidad del medio, al tiempo que de ella dependerá su capacidad de generalización simbólica.

Es cierto que para Luhmann la diferenciación plena de los medios de consecución solo se da en una sociedad funcionalmente diferenciada, pero una sociedad de este tipo no habría sido posible sin el desarrollo de los medios de consecución. Justamente por ello tiene sentido estudiar la evolución histórica del problema de partida del poder; examinar qué soluciones se inventaron en cada contexto cultural, cuáles se estabilizaron, cuáles se rechazaron y cómo las selecciones hechas por otros sistemas en el entorno condicionaron e irritaron las selecciones hechas por el sistema tomado como referencia. Aquí el concepto de selecciones positivas y negativas y la concepción de la reestabilización sistémica, que pone en juego la compatibilidad de las estructuras, ofrece un marco teórico que vale la pena explorar.

Ahora bien, el problema del poder es distinto del problema de referencia de la política, a saber, la toma de decisiones vinculantes colectivas. Este también es un problema que todo sistema social debe resolver independiente de su nivel de complejidad. Que el poder permita la toma de decisiones vinculantes colectivas es tan evidente para la mentalidad occidental que pensarlo parece una perogrullada. Pero una visión histórico-evolutiva -e incluso desde una antropología del poder- permite constatar que la religión, la magia, el chamanismo o la pertenencia a un grupo, o bien un clan, o bien una corporación medieval, fungen como equivalentes funcionales a la toma de decisiones vinculantes colectivas. Querer ver aquí de nuevo el poder es confundir las cosas; la otra alternativa es distinguir entre poder y poder político; pero, actualmente, esta distinción tiene más de formalidad que de capacidad analítica. Por ende, esta conexión entre poder y política - por decirlo así- debería estar sujeta al escrutinio histórico y contemplarse en su contingencia, en vez de darse por sentada.

En este orden de ideas, se sugiere que la teoría del poder de Luhmann (2000, 2005) permite distinguir tres elementos indispensables para que el problema de referencia de la política (capacidad de tomar decisiones vinculantes colectivas) se desplace del ámbito general de la influencia social hacia el poder político (motivación por vía de la selectividad); es decir, estos tres elementos permiten evaluar en cada caso cómo se articulan históricamente poder y política. Estos son la organización, la simbolización y la instrumentalización del poder.

El poder para ser capaz de estabilizarse y adquirir complejidad necesita organizarse (Luhmann, 2005). Organizar el poder significa, por un lado, establecer rangos y jerarquías en la administración de la violencia, y por el otro, la diferenciación cargo/ persona para el cumplimiento de diversas tareas administrativo-burocráticas. En ausencia de tales estructuras, y faltando la diferenciación de un tipo de comunicación basado en la recursividad de las decisiones, serían grandes las dificultades para la 
rearticulación de las redundancias y la diferenciación de un medio que disuelva la estructura multifuncional de la sociedad.

Naturalmente, en la evolución sociocultural, han emergido distintas formas de organización del poder. Lo definitivo para que este logre organizarse consiste en la disponibilidad duradera y relativamente estable de la posibilidad del condicionamiento de las acciones de alter y de ego con la amenaza con el ejercicio de la violencia física como alternativa que tanto alter como ego quieren evitar (Luhmann, 2005) o también mediante la oferta o amenaza de retiro de sanciones positivas.

De igual modo, el poder requiere - como condición de su circulación- la simbolización (Luhmann, 2005). Los símbolos del poder hacen presente lo ausente; representan la autoridad, la virtud, la fortaleza, y tantas otras cosas que se quieran asociar con el poder. Los símbolos políticos son imprescindibles en la comunicación del poder, pues, entre otras cosas, crean y sostienen identidades que servirán a su vez como criterio de membresía para la organización del poder y, sobre todo, la simbolización del poder actualiza la alternativa indeseable del recurso a la violencia como condicionante de la acción. Lo descrito sirve a la generalización simbólica referida por Luhmann en cuanto habilita el medio para activarse en pluralidad de ocasiones y situaciones (Luhmann, 1998).

Y finalmente, para que el poder pueda hacerse forma debe instrumentalizarse. Esto lo realiza principalmente con sanciones positivas y negativas, cuya diferenciación trae aparejada la formación de organizaciones particulares. En la imposición de sanciones negativas, tendríamos al Ejército y a la Policía, mientras que en las sanciones positivas sería imprescindible una estructura burocrática o alguna forma de organización social y territorial que administre tales recursos (Luhmann, 2005,). La instrumentalización del poder está sujeta a disposiciones materiales concretas; en este sentido, depende de la constelación de posibilidades que en el tiempo y en el espacio permitan coordinar acciones que amenacen con la imposición de sanciones positivas o negativas. Y depende también de cómo estas posibilidades sean observadas (juzgadas y por tanto moralizadas) por terceros.

Cuandoquiera que observemos estas tres condiciones, por más incipientes que puedan ser, estaríamos en presencia de una forma de organización del poder. Este es un concepto alternativo al de Estado, que resulta demasiado eurocéntrico y sobredeterminado cultural e históricamente.

Ahora bien, la constitución de un sistema mundo funcional para la política obedece a un proceso que desde la historia global está siendo actualmente estudiado con la constitución de redes comerciales que traficaban con mercancías, ideas, noticias y movilizaban personas de un lugar a otro (Armitage y Subrahmanyam, 2010). Pero también obedece a un proceso que ya es bien conocido: los procesos de colonización y de consolidación hegemónica de los Estados europeos alrededor del globo. Esto tuvo por efecto la difusión de los estándares políticos y culturales occidentales como baremo de 
modernización. De esta manera, las diversas formas de organización del poder sufrieron un proceso de estandarización, que, si bien cambió sus caras, no ha significado de ninguna manera un proceso de homogeneización (Eisenstadt, 2000). Ambos procesos han ejecutado la integración comunicativa del mundo.

Este sistema político-mundo se diferencia en tres niveles, los cuales son estructuras que como puntos de contacto internos dirigen la comunicación política y crean al mismo tiempo variedad y redundancia. El primer nivel discrimina la pertenencia o no de las comunicaciones al sistema político; se trata de la diferencia sistema/entorno. A continuación, tenemos la diferencia nacional/internacional o doméstico/foráneo, la cual organiza los temas de decisión política en función de su ámbito de competencia, donde el concepto de soberanía sirve para enfocar cuáles asuntos se reclaman como de la competencia exclusiva de determinada organización de poder y frente a cuáles se estaría dispuesto a cooperar. El lado externo de la distinción también puede remitir la comunicación a organizaciones de poder de nuevo cuño, a saber, las organizaciones internacionales. En el estado actual del derecho internacional público, las organizaciones internacionales son capaces de imponer sanciones positivas y negativas a través del Consejo de Seguridad de las Naciones Unidas. Con esta selección de estructura comunicativa, pretendemos resolver el problema de referencia sistémica que surge al incluir un sistema interestatal como subsistema del sistema político-mundo y a la vez entender el Estado como organización. Consecuentemente, las organizaciones formarían parte del entorno del sistema y lo que prevalece en este son diferencias que reproducen la comunicación política.

$\mathrm{Y}$, por último, tenemos la diferencia centro/periferia que resulta de la autoorganización de la comunicación alrededor de núcleos de decisión relacionados con un entramado en red de instancias comunicativas que integran el circuito de poder. La autoorganización de la comunicación en centro/periferia puede observarse en el seno de una forma de organización del poder, del mismo modo que ha sido descrita por Luhmann que caracteriza la conexión entre política, administración y público. Pero también puede observarse en la política internacional, donde surgen "potencias de primer y segundo orden", la mayoría integrando "la comunidad internacional" y un lumpen de "Estados forajidos" y "Estados fallidos". Tanto el segundo como el tercer nivel de diferenciación interno del sistema político-mundo requieren las organizaciones (y no solo organizaciones de poder), pues, como afirma Luhmann, estas son el único sistema social capaz de comunicar en nombre propio; y no solo eso, sino que también las organizaciones constituyen el entorno social con la suficiente complejidad requerida para mantener la forma de diferenciación funcional de la sociedad moderna (Luhmann, 2006).

Hasta aquí todo bien. Pero este planteamiento aún no confiere una alternativa frente a los objetivos propuestos. Tal cambio de paradigma todavía debe adelantar una clave hermenéutica alternativa para estudiar los procesos de la política interior. Es decir, ¿qué 
herramientas nos ofrece el marco teórico de la evolución del poder para la comprensión de los regímenes políticos y su estabilidad?

Una idea propuesta por Luhmann cuando abordaba la evolución política puede resultar aquí de suma utilidad. Se trata de un préstamo conceptual de la física a la sociología: las estructuras disipativas de Prigogine (1997; Luhmann, 2000). Una estructura disipativa es una forma temporal de autoorganización que surge en un sistema abierto al intercambio constante de energía con su entorno y que, por tanto, se convierte en un sistema no lineal y lejano al equilibrio. Esta idea de la transformación de la disposición caótica interna en organización podría servirnos para representarnos teóricamentelos procesos políticos interiores.

El concepto de estructura disipativa es compatible con la diferencia sistema/entorno, porque nos dice que el sistema se autoorganiza y establece intercambios con un entorno fluctuante, cuyas inestabilidades afectan también los equilibrios internos que conducen a la modificación de las estructuras. Así pues, si hablamos de autoorganización dentro de una organización del poder, tendríamos que referirnos a la diferenciación entre política, administración y público. Eso, por un lado, y por otro, habríamos de remitirnos también a los ciclos formales e informales del poder. Y en cuanto al entorno habríamos de marcar como referencia sistémica el entorno interno del sistema político-mundo (con todos los niveles de diferenciación señalados), el sistema jurídico, el sistema económico, el sistema de los medios de masas, el sistema de la ciencia y el sistema religioso, por nombrar los que más irritación producen al sistema político.

Dando por supuesto que existe más de una forma de configuración de las relaciones entre política, administración y público, se puede afirmar que:

- La organización territorial del poder en una forma concreta depende de si se han privilegiado las sanciones positivas o las negativas para lograr la aceptación de la comunicación.

- La diferenciación de cada ámbito de interacción no solo requiere una base organizativa (ejércitos, burocracias, públicos), sino también funcional (Luhmann, 2007), que existan estructuras de expectativas estables que permitan tal despliegue.

- La politización de la Administración puede llevar a la intervención de los militares en la política, lo que supondría tener que agregar las Fuerzas Armadas como otro elemento dentro del circuito de poder.

- El devenir histórico de cada organización del poder es particular y particularizado por la construcción de una memoria y unas identidades.

Siguiendo estos razonamientos, tendría sentido hablar de configuraciones cíclicas del poder, con el objeto de señalar los equilibrios dinámicos que se alcanzan dentro de determinada organización durante un intervalo de tiempo determinado. 
Para comprender estas configuraciones cíclicas, sería instructivo examinar los ciclos formales e informales, sin embargo, lo que nos deja Luhmann es más bien una descripción empírica basada en su comprensión de la democracia liberal. Habría que generalizar aquellos conceptos y definir en qué consiste la formalidad del ciclo y en qué su informalidad.

Para Luhmann, el ciclo informal es el que se efectúa con regularidad en los asuntos políticos, mientras que el ciclo formal es aquel que se impone en casos de conflicto; el primero se basa en la sobrecarga de complejidad del sistema, mientras que el segundo se sirve de las prestaciones del sistema jurídico para conferirle complejidad al poder (Luhmann, 1997). Si seguimos esta idea, tendría sentido complementar la distinción formal/informal con aquella de visibilidad/invisibilidad. Y es que el poder dentro de un contexto de observación de segundo orden es siempre escenificación; y lo que se expone al público siempre tiene un trasfondo. De esta manera, el ciclo formal del poder correspondería con la autodescripción normativa del proceso político interno, la cual, si bien eventualmente no se impone en caso de conflicto, debería por lo menos brindar suficientes condiciones de verosimilitud para de esta forma validar los valores que se ostentan: producir legitimidad (Luhmann, 2000). Mientras que el ciclo informal se remite a la autodescripción de la situación propia de los roles públicos y a la estructura que constriñe las acciones y vivencias de quienes los asumen, el ciclo informal, en consecuencia, se refiere a la configuración fáctica del proceso de formación de consensos y toma de decisiones vinculantes colectivas.

Ahora bien, hablaríamos de distintas configuraciones cíclicas del poder en función de cómo la autoorganización de política, administración y público, junto con los ciclos y contraciclos del poder, se arreglan frente a las fluctuaciones del entorno interno y externo del sistema político. Podríamos distinguir entre configuraciones estables, hiperestables e inestables, entendiendo que la presunción de estabilidad se basa en el principio de la existencia de un equilibrio dinámico, de un flujo estocástico, de una tendencia en un diagrama de dispersión, entre otros esquemas teóricos o principios que abundan sobre la misma idea.

Existiría una configuración cíclica estable del poder cuando un soporte organizacional sirve para mantener una diferenciación formal entre política, administración y público (ciclo formal), pero los sistemas de interacción se arreglan en configuraciones fluctuantes dependiendo de en cuál elemento del circuito se monopolicen mayores recursos de poder (por tales entenderemos la disposición del recurso a la violencia física - dirigir un organismo policial, de inteligencia o militar o contar con la lealtad de quienes lo dirigen-, la disposición de recursos monetarios y financieros, la monopolización de las instancias representativas de "la voz del pueblo" - representantes estudiantiles, sindicales, gremiales, la tribuna periodística y, por supuesto, los puestos en la estructura de cargos de la organización del poder-y, en función del acoplamiento estructural política-persona, 
el carisma, el liderazgo o la autoridad) o bien si estos se distribuyen más o menos parejamente (ciclo informal). La incidencia de las fluctuaciones del entorno sobrecarga la capacidad de procesamiento de la información de los sistemas de interacción en juego, por lo cual se suele recurrir a mecanismos de reducción de la complejidad, incapaces de convertir la complejidad inasible en una mayor riqueza estructural. La complejidad indeterminada se transforma atendiendo a los códigos del sistema, pero ello no deriva en una riqueza de opciones para el sistema, sino en un reforzamiento de las selecciones ya realizadas. En consecuencia, la capacidad de aprendizaje es reducida o moderada.

En una configuración cíclica hiperestable del poder, el soporte organizacional de la diferenciación entre política, administración y público asume la mayor carga de procesamiento de la información, y los recursos de poder están distribuidos de tal manera que este como medio de consecución alcanza reflexividad (es decir que "institucionalmente" existen disposiciones para que el poder limite el poder). En estos casos, el ciclo formal puede imponerse efectivamente en caso de conflicto. Los sistemas de interacción, por su parte, reproducen la diferenciación política, la administración y el público, y en conjunto terminan por resultar en un mecanismo de compensación de la complejidad generada por el mismo sistema (ciclo informal). De esta forma, se produce una suerte de doble cerradura (Von Foerster, 1993) que le permite al sistema reintroducir una instancia de negación dentro de sí mismo, lo cual lo faculta para orientarse frente a su entorno con suficiente capacidad de aprendizaje. El sistema se hace más flexible y más inflexible al mismo tiempo: más flexible porque puede modificar sus estructuras para alcanzar nuevos equilibrios y más inflexible porque es capaz de mantener esa doble cerradura a pesar de las fluctuaciones del entorno. El medio absorbe las fluctuaciones con los programas (varianza), pero conserva sus codificaciones (invarianza), a diferencia de una configuración cíclica estable del poder donde varían tanto los programas como los códigos y sus relaciones.

Por último, tenemos las configuraciones cíclicas inestables del poder. En este caso, existen tres posibilidades: la primera, que el poder se constituya en un solo ciclo, el fáctico; la segunda, que el poder no se autoorganice autorreferencialmente, sino que se disponga jerárquicamente; y la tercera, que el mismo hecho de la organización del poder esté en entredicho. En el primer caso, el ciclo del poder no necesariamente ha de organizarse entre política, administración y público, pudiendo existir una marcada unificación entre política y administración en relación con un ámbito de publicidad poco segmentado y cuasiunitario. En el segundo caso, el público es desconectado del circuito de poder, por lo cual el proceso político dependería de las tríadas formadas por aquellos sistemas de interacción que monopolizan los recursos de poder (por ejemplo la relación Fuerza Armada-líder-burocracia). Y, en el último caso, tendríamos una formación social jerárquica multifuncional que asume funciones políticas junto con las económicas o religiosas. Las configuraciones cíclicas inestables del poder son 
hipocomplejas, tienen poca capacidad de aprendizaje y son susceptibles de ser disueltas por su entorno (desdiferenciación). Por esta razón, las organizaciones internacionales del poder o algunas potencias suelen suplir (o se enfrentan a ese problema) la función de universalidad específica que debería cumplir la organización de poder (Luhmann, 1999).

Naturalmente, no es posible agotar en un artículo la cantidad de temas por explorar y dudas por despejar que inevitablemente surgen cuando se adelanta un nuevo paradigma. Sobra decir que la tesis de las configuraciones cíclicas del poder tiene mucho de hipótesis de trabajo, por lo cual sería prudente realizar estudios que permitan confirmar que las variables seleccionadas realmente alcanzan los tres tipos de estabilidad descritos, sobre todo, estudios históricos y análisis de casos. Quizá el recurso a simulaciones en computador basándonos en la teoría de los sistemas dinámicos, la teoría de redes u otras ofertas teóricas del campo de la complejidad podría arrojar algunos modelos que poner a prueba, aunque la intratabilidad de muchas de las variables manejadas es todavía un gran obstáculo que superar por los modelos matemáticos. A pesar de todo, si he logrado fijar algunos puntos clave que permitan abrir un debate que reflexione sobre los obstáculos epistemológicos que ha heredado la ciencia política en su lenguaje teórico, se habrá cumplido con creses el objetivo propuesto.

\section{Referencias}

Anderson, P. (1987). El Estado absolutista. México: Siglo XXI.

Arendt, H. (2004). Los orígenes del totalitarismo. Madrid: Taurus.

Aristóteles (2007). Política. Madrid: Gredos.

Armitage, D. y Subrahmanyan, S. (2010). The age of Revolutions in global context c.176o-1840. Nueva York: Palgrave Macmillan.

Arnason, J. (2003). Civilizations in dispute: Historical questions and theoretical traditions. Leiden: Brill.

Arnason, J. (2010). Domains and perspectives in civilizational analysis. European Journal of Social Theory, 13(1), 5-13.

Bachelard, G. (2007). La formación del espíritu científico. Buenos Aires: Siglo XXI.

Baecker, D. (2007). Form und Formen der Kommunikation. Frankfurt am Main: Suhrkamp.

Barber, B. (2004). Strong democracy. Berkeley: University of California Press.

Bateson, G. (2006). Espíritu y naturaleza. Buenos Aires: Amorrortu.

Beck, U. (2002). Libertad o capitalismo. Barcelona: Paidós. 
Beyme, K. von (2002). Der Staat des politischen Systems im Werk Niklas Luhmanns. En K.-U. Hellmann y R. Schmalz-Bruns (eds.), Theorie der Politik: Niklas Luhmanns politische Soziologie (pp. 131-148). Frankfurt am Main: Suhrkamp.

Blanco Rivero, J. J. (2009). El lenguaje de la ciencia política en El Observador caraqueño, 1824-1825. En Imprentas y periódicos de la Emancipación: a dos siglos de la Gaceta de Caracas: memoria de las VIII Jornadas de Historia y Religión (pp. 147174). Caracas: Fundación Konrad Adenauer/Universidad Católica Andrés Bello.

Blanco Rivero, J. J. (2012). Una teoría operativa del significado. Ariadna histórica. Lenguajes, conceptos, metáforas, 1, 41-79. Recuperado de http://www.ehu.eus/ ojs/index.php/Ariadna/article/view/6130/pdf

Blanco Rivero, J. J. (2013). iRefórmese el Gobierno y los individuos se reformarán! Elementos de una teoría política venezolana de la emancipación, 1808-1830. Saarbrücken: Dictus Publishing.

Bobbio, N. (2008) La teoría de las formas de gobierno en la historia del pensamiento político. México: Fondo de Cultura Económica.

Cansino, C. (1998). Historia de las ideas políticas: fundamentos filosóficos y dilemas metodológicos. México: Centro de Estudios de Política Comparada.

Castro Leiva, L. (2009). Teoría política y ética de la independencia. En L. Castro Leiva, Obras (vol. 2, pp. 528-645). Caracas: Fundación Polar/Universidad Católica Andrés Bello.

Chiaramonte, J. C. (2004). Nación y Estado en Iberoamérica: el lenguaje político en tiempos de las independencias. Buenos Aires: Sudamericana.

Constant, B. (2010). Principios de política aplicables a todos los gobiernos. Buenos Aires: Katz.

Derathé, R. (1979). Jean-Jacques Rousseau et la science politique de son temps. París: Librairie philosophique J. Vrin.

Deutsch, K. W. (1980). Los nervios del gobierno: modelos de comunicación y control políticos. Buenos Aires: Paidós.

Easton, D. (1968). Política moderna. México: Letras.

Easton, D., Graziano, L. y Gunnell, J. (eds.) (2002). The development of political science: A comparative survey. Londres: Routledge.

Eisenstadt, S. N (2000). Multiple modernities. Daedalus, 129, 1-29. 
Foerster, H. von (1993). Über das Konstruiren von Wirklichkeiten. En H. von Foerster, Wissen und Gewissen. Versuch einer Brücke (pp. 25-49). Frankfurt am Main: Suhrkamp.

Foucault, M. (2006a). La arqueología del saber. México: Siglo XXI.

Foucault, M. (2006b). Seguridad, territorio, población. Buenos Aires: Fondo de Cultura Económica.

Franke, H. y Trauzettel, R. (1989). El imperio chino. México: Siglo XXI.

Friedrich, C. J. y Brzezinski, Z. (1975). Dictadura totalitaria y autocracia. Buenos Aires: Libera.

García-Pelayo, M. (1991a). Del mito y de la razón en la historia del pensamiento político. En Obras completas (vol. 2). Madrid: Centro de Estudios Constitucionales.

García-Pelayo, M. (1991b). Tipos representativos: una contribución al estudio de las modalidades tipológicas. En Obras completas (vol. 3). Madrid: Centro de Estudios Constitucionales.

Gelderen, M. van y Skinner, Q. (2002). Republicanism: A shared European Heritage. Cambridge: Cambridge University Press.

Gierke, O. (1958). Johannes Althusius und die Entwicklung der naturrechtlichen Staatstheorien. Aelen: Anton Hain Verlag.

Gilbert, L. y Mohseni, P. (2011). Beyond authoritarianism: The conceptualization of hybrid regimes. Studies in Comparative International Development, 46(3), 270-297.

Guevara, P. (1997). Estado vs. democracia. Caracas: Universidad Central de Venezuela.

Guriev, S. M. y Treisman, D. (2015). How modern dictators survive: Cooptation, censorship, propaganda and repression. CEPR Discussion Paper DP10454. Recuperado de https://papers.ssrn.com/sol3/papers.cfm?abstract_id=2572452

Harrington, J. (1987). La república de Océana. México: Fondo de Cultura Económica.

Harris, R. (1981). The language myth. Londres: Duckworth.

Held, D. (1997). La democracia y el orden global. Barcelona: Paidós.

Hintze, O. (1968). Esencia y difusión del feudalismo. En Historia de las formas políticas (pp. 37-77). Madrid: Revista de Occidente.

Holz, K. (2003). Politik und Staat: Differenzierungstheoretische Probleme in Niklas Luhmanns Theorie des politischen Systems. En K. U. Hellmann, K. Fischer y H. Bluhm (eds.), Das System der Politik: Niklas Luhmanns politische Theorie (pp. 34-48). Wiesbaden: Westdeutscher Verlag. 
Hourani, A. (2010). La historia de los árabes. Barcelona: Zeta.

Johnson, N. (1991). Los límites de la ciencia política. Madrid: Tecnos.

Latour, B. (2013). An inquiry into modes of existence. Londres: Harvard University Press.

Leal Curiel, C. (2011). Estudio preliminar: el Congreso General de Venezuela, 1811-1812: disyuntivas de la confederación. En Libro de Actas del Supremo Congreso de Venezuela, 1811-1812 (t. 1). Caracas: Academia Nacional de la Historia.

Levitsky, S. y Way, L. (2010). Competitive authoritarianism: Hybrid regimes after the cold war. Nueva York: Cambridge University Press.

Luhmann, N. (1991). Systemtheorie, Evolutionstheorie und Kommunikationstheorie. En N. Luhmann, Soziologische Aufklärung 2 (pp. 193-203). Wiesbaden: Springer.

Luhmann, N. (1992). Die Wissenschaft der Gesellschaft. Frankfurt am Main: Suhrkamp.

Luhmann, N. (1997). Teoría política en el estado de bienestar. Madrid: Alianza Editorial.

Luhmann, N. (1998). Die Gesellschaft der Gesellschaft. Frankfurt am Main: Suhrkamp.

Luhmann, N. (1999). Metamorphosen des Staates. En N. Luhmann, Gesellschaftsstruktur und Semantik 4 (pp. 101-137). Frankfurt am Main: Suhrkamp.

Luhmann, N. (2000) Die Politik der Gesellschaft. Frankfurt am Main: Suhrkamp.

Luhmann, N. (2005). Poder. México: Anthropos.

Luhmann, N. (2006). Organisation und Entscheidung. Wiesbaden: VS Verlag.

Luhmann, N. (2007). Politische Planung. Wiesbaden: VS Verlag.

Luhmann, N. (2008). Sinn, Selbstreferenz und soziokulturelle Evolution. En Ideenevolution (pp. 7-71). Frankfurt am Main: Suhrkamp.

Luhmann, N. (2010). Politische Soziologie. Berlín: Suhrkamp.

Ottaway, M. (2003). Democracy challenged: The rise of semiauthoritarianism. Washington DC: Carnegie Endowment for International Peace.

Pocock, J. G. A. (1989). Languages and their implications: The transformation of the study of political thought. En Politics, language and time (pp. 3-41). Chicago: University of Chicago Press.

Pocock, J. G. A. (1990). The concept of a language and the métier d'historien: Some considerations on practice. En A. Pagden (ed.), The languages of political theory in Early-Modern Europe (pp. 19-40). Cambridge: Cambridge University Press. 
Pocock, J. G. A. (1995). Introduction: The state of the art. En Virtue, commerce, and history: Essays on political thought and history, chiefly in the eighteenth century (pp. 1-36). Cambridge: Cambridge University Press.

Pocock, J. G. A. (2002). El momento maquiavélico: el pensamiento político florentino y la tradición republicana atlántica. Madrid: Tecnos.

Prigogine, I. (1997). Las leyes del caos. Barcelona: Drakontos.

Rupnik, J. (1991). El totalitarismo visto desde el este. En G. Hermet, Totalitarismos (pp. 50-83). México: Fondo de Cultura Económica.

Rus Rufino, S. (2001). Evolución de la noción de derecho natural en la ilustración española. Cuadernos Dieciochescos, 2, 229-259.

Saeidi, S. (2006). International political system and the Westphalian paradigm: A call for revision. Digest of Middle East Studies, 15(2), 11-25.

Schmitt, C. (2006). El concepto de lo político. Madrid: Alianza Editorial.

Senellart, M. (1995). Les arts de gouverner. París: Editions Du Seuil.

Shedler, A. (2006). Electoral authoritarianism: The dynamics of unfree competition. Boulder: Lynne Rienner.

Shklar, J. (1990). Alexander Hamilton and the language of political science. En A. Pagden (ed.), The languages of political theory in early-modern Europe (pp. 339-355). Cambridge: Cambridge University Press.

Skinner, Q. (1993). Los fundamentos del pensamiento político moderno (vol. 2). México: Fondo de Cultura Económica.

Skinner, Q. (1996). Reason and rhetoric in the philosophy of Hobbes. Cambridge: Cambridge University Press.

Skinner, Q. (1998a). La libertad antes del liberalismo. Madrid: Taurus.

Skinner, Q. (1998b). Maquiavelo. Madrid: Alianza Editorial.

Smith, J. (2002). Theories of state formation and civilisation in Johann P. Arnason and Shmuel Eisenstadt's comparative sociologies of Japan. Critical Horizons, $3(2), 225-251$.

Stichweh, R. (2002). Politik und Weltgesellschaft. En K.-U. Hellmann y R. SchmalzBruns (eds.), Niklas Luhmanns politische Soziologie (pp. 287-296). Frankfurt am Main: Suhrkamp. 
Stourzh, G. (1988). Constitution: changing meanings of the term from the early Seventeenth to the late Eighteenth century. En T. Ball y J. G. A. Pocock (eds.), Conceptual change and the Constitution (pp. 35-54). Kansas: University Press of Kansas.

Tilly, C. (1992). Coerción, capital y los Estados europeos, 990-199o. Madrid: Alianza Editorial.

Tuck, R. (1979). Natural rights theories: Their origin and development. Cambridge: Cambridge University Press.

Tully, J. (1995). Strange multiplicity: Constitutionalism in an age of diversity. Cambridge: Cambridge University Press.

Viroli, M. (2009). De la política a la razón de Estado: la adquisición y transformación del lenguaje político (1250-16oo). Madrid: Akal.

Voegelin, E. (2006). La nueva ciencia de la política: una introducción. Buenos Aires: Katz. 
